\title{
Follicular lymphoma Grade 1 of the minor duodenal papilla successfully diagnosed by endoscopic papillectomy
}

A 70-year-old asymptomatic woman underwent screening esophagogastroduodenoscopy, which revealed a bulging minor duodenal papilla with redness and rough surface ( $\mathbf{F i g} \cdot \mathbf{1} \mathbf{a}-\mathbf{c}$ ). Biopsy was suggestive of adenocarcinoma. Laboratory data included normal blood counts and standard serum biochemical tests. Abdominal computed tomography (CT) showed a slightly contrast-enhanced duodenal tumor, approximately $1 \mathrm{~cm}$ in size without regional lymphadenitis in the second part of the duodenum; however, choledocholith was also noted inci- dentally (> Fig.2a). Magnetic resonance cholangiopancreatography and endoscopic retrograde cholangiopancreatography (ERCP) showed a normal pancreatic duct ( $\mathbf{F i g . 2} \mathbf{b}, \mathbf{c}$ ) and choledocholith.

The choledocholith was removed and endoscopic biliary stenting was performed by ERCP. We then performed endoscopic papillectomy of the minor duodenal papilla to confirm the diagnosis ( $\mathbf{F i g . 1}$ d-f, - Video 1). Histological and immunohistochemical examination revealed follicular lymphoma Grade 1, which was positive for CD20/CD10/BCL-2 but negative for CD3/CD5/BCL1 ( Fig.3). Bone marrow biopsy showed no abnormal findings; however, 18-F fluorodeoxyglucose-positron emission tomography/ computed tomography revealed uptake in the third part of the duodenum and surrounding lymph node ( $\bullet$ Fig. $\mathbf{2 d}$ ), indicating a diagnosis of stage II1 (Lugano International Conference Classification). The patient progressed well after endoscopic papillectomy and was discharged 10 days postoperatively. Following advice from the hematologist, the patient
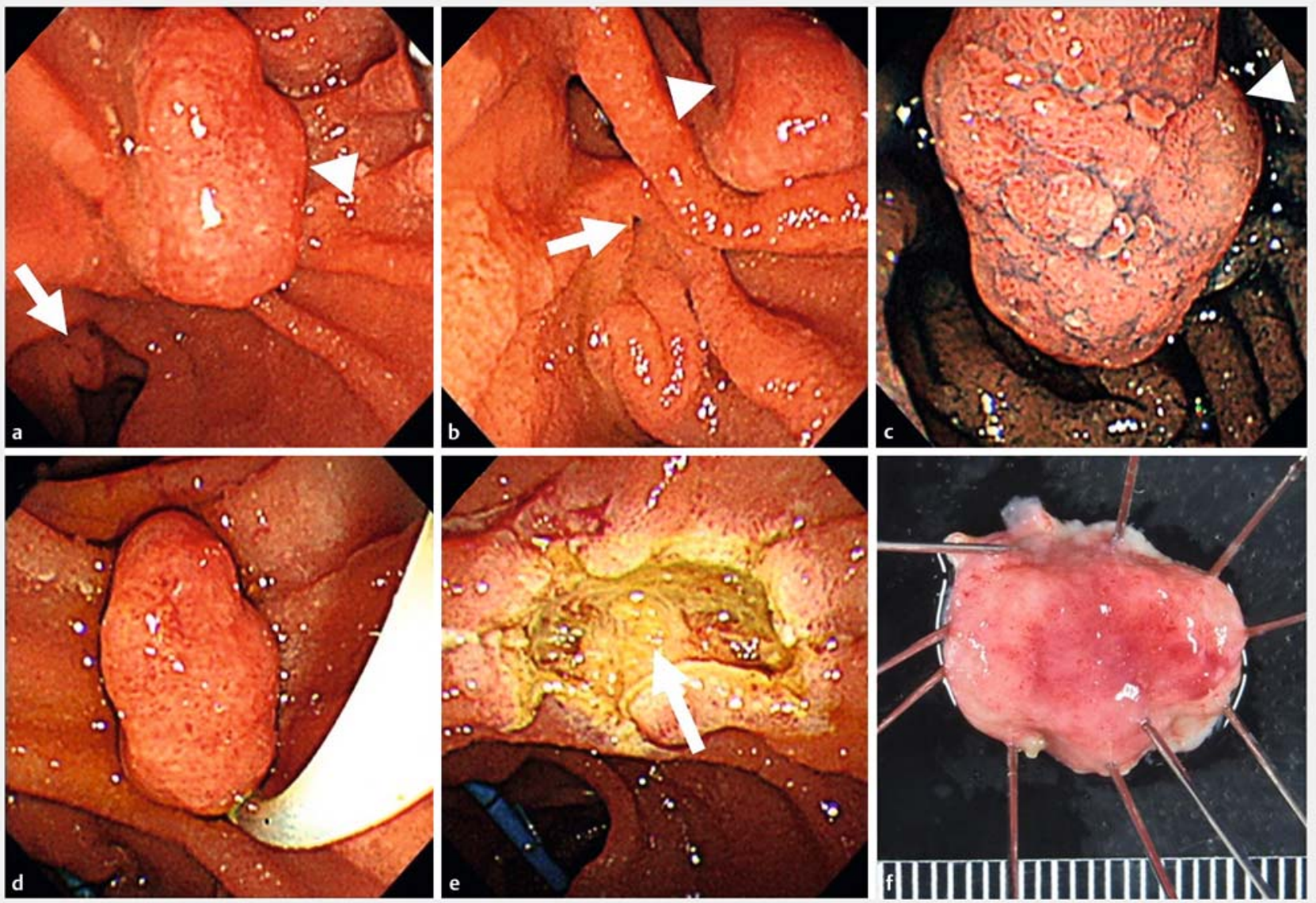

- Fig. 1 Treatment of the tumor. Endoscopic views (a-e). a-c The minor duodenal papilla with a tumor causing redness and rough surface (arrowheads). The ampulla of Vater was intact (arrows). $\mathbf{d}$ Endoscopic papillectomy of the minor duodenal papilla along with resection of the tumor using a polypectomy snare. e Immediately after endoscopic papillectomy, the orifice of the Santorini duct was confirmed (arrow). f The resected specimen, approximately $1.7 \mathrm{~cm}$ in size. 

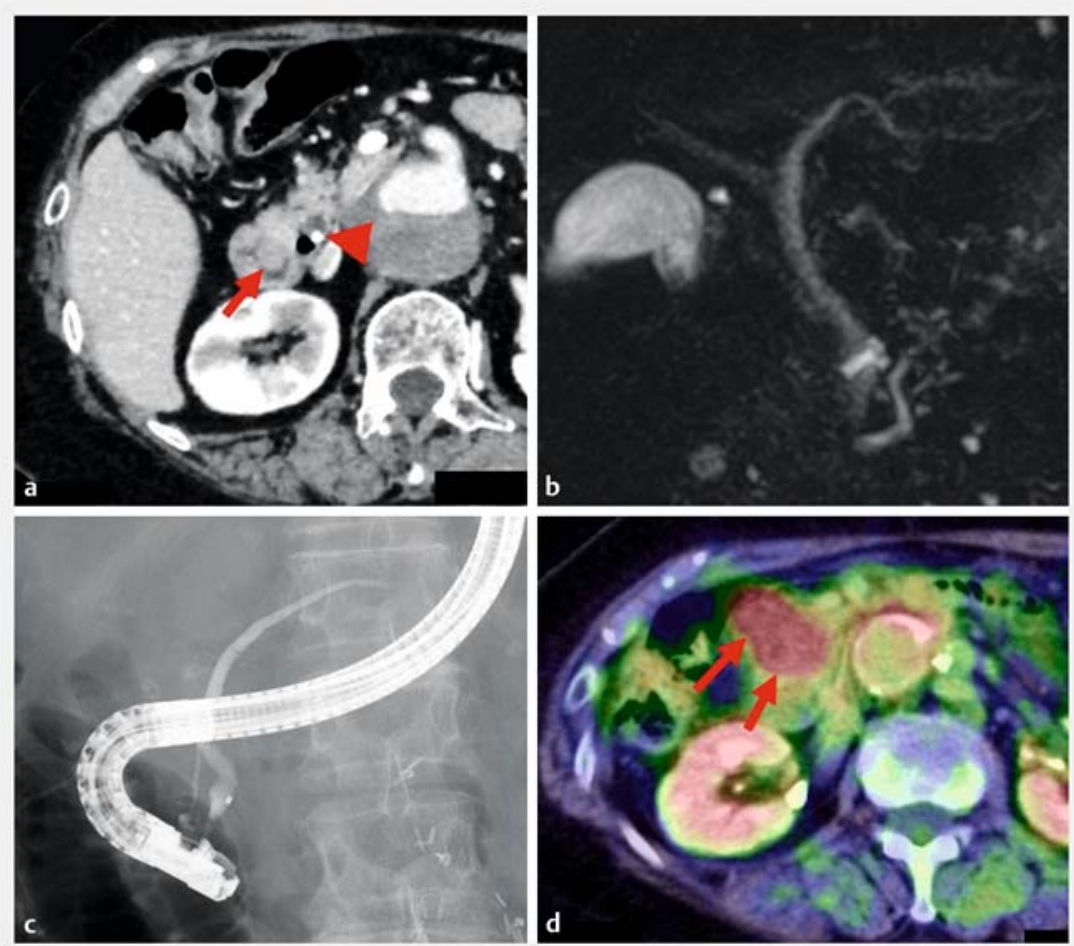

- Fig. 2 Imaging studies. a Abdominal computed tomography scan, showing a slightly contrast-enhanced duodenal tumor, approximately $1 \mathrm{~cm}$ in size without regional swollen lymph nodes in the second part of the duodenum (arrow) and an incidental choledocholith (arrowhead). b, c Magnetic resonance cholangiopancreatography (b) and endoscopic retrograde cholangiopancreatography (c) showed a normal pancreatic duct. d 18-F fluorodeoxyglucosepositron emission tomography/computed tomography after endoscopic papillectomy showed uptake in the third part of the duodenum and surrounding lymph node (arrows)
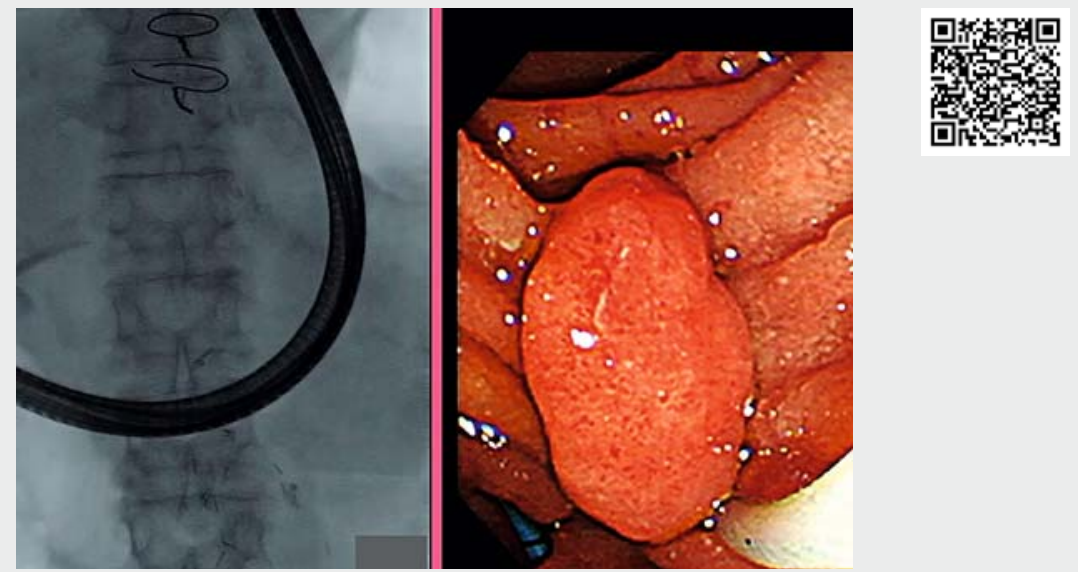

Video 1 Endoscopic papillectomy of the minor duodenal papilla and resection of the tumor using a polypectomy snare after removal of a choledocholith and endoscopic biliary stenting by endoscopic retrograde cholangiopancreatography.
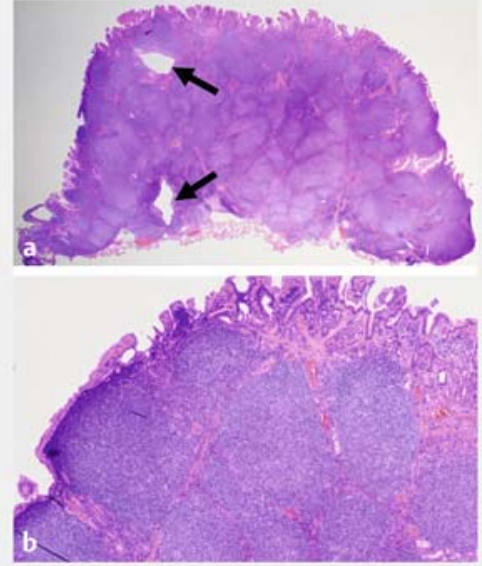

Fig. 3 Histological images of the resected specimen stained with hematoxylin and eosin, showing follicular lymphoma Grade 1. The Santorini duct was confirmed (arrow). $\mathbf{a} \times 12.5 . \mathbf{b} \times 60$.

commenced watch-and-wait monitoring.

Follicular lymphoma of the duodenum is rare, comprising only $3.6 \%$ of all gastrointestinal tract lymphomas [1]. Follicular lymphoma of the minor duodenal papilla is very rare. In addition, only a few cases of minor duodenal papilla tumors other than adenocarcinoma, such as somatostatinoma and carcinoid, have been reported to be treated with endoscopic papillectomy [2,3]. To the best of our knowledge, this is the first case report in English of a follicular lymphoma of the minor duodenal papilla being successfully diagnosed using endoscopic papillectomy. Endoscopic papillectomy may provide an endoscopic technique for diagnosis of the follicular lymphoma of the minor duodenal papilla.

Endoscopy_UCTN_Code_CCL_1AB_2AZ_3AB

\section{Competing interests}

The authors declare that they have no conflict of interest. 
Takashi Abe ${ }^{1}$, Kosuke Kodama', Takayuki Nagai ${ }^{1}$, Koki Yamanaka ${ }^{1}$, Masato Hanzawa ${ }^{1}$, Takafumi Yano', Kazunari Murakami²

1 Department of Gastroenterology, Oita Kouseiren Tsurumi Hospital, Beppu, Japan

2 Department of Gastroenterology, Faculty of Medicine, Oita University, Yufu, Japan

\section{Corresponding author}

\section{Takashi Abe, MD, PhD}

Department of Gastroenterology, Oita Kouseiren Tsurumi Hospital, Tsurumi 4333, Beppu City, Oita 874-8585, Japan

Fax: +81-977-237884

takashi0315@oita-u.ac.jp
[1] Yoshino T, Miyake K, Ichimura K et al. Increased incidence of follicular lymphoma in the duodenum. Am J Surg Pathol 2000; 24: 688-693

[2] Jara Letelier DI, Bonotto ML, Ardengh JC. Somatostatinoma of the minor duodenal papilla associated with pancreas divisum treated by endoscopic papillectomy. Endoscopy 2016; 48: E135-E137

[3] Itoi T, Sofuni A, Itokawa F et al. Endoscopic resection of carcinoid of the minor duodenal papilla. World J Gastroenterol 2007; 13 : 3763-3764

Bibliography

Endoscopy 2021; 53: E35-E37

DOI 10.1055/a-1173-8418

ISSN 0013-726X

published online 29.5.2020

(c) 2020. Thieme. All rights reserved.

Georg Thieme Verlag KG, Rüdigerstraße 14,

70469 Stuttgart, Germany

\section{ENDOSCOPY E-VIDEOS}

https:/|eref.thieme.de/e-videos

口回 Endoscopy E-Videos is a free access online section, reporting 回舴: on interesting cases and new techniques in gastroenterological endoscopy. All papers include a high quality video and all contributions are freely accessible online.

This section has its own submission website at

https://mc.manuscriptcentral.com/e-videos 